\title{
Extracellular lipid loading augments hypoxic paracrine signaling and promotes glioma angiogenesis and macrophage infiltration
}

Svenja Offer ${ }^{1,2+}$, Julien A. Menard ${ }^{1 \dagger}$, Julio Enríquez Pérez ${ }^{3+}$, Kelin G. de Oliveira ${ }^{1}$, Vineesh Indira Chandran ${ }^{1}$, Maria C. Johansson ${ }^{1}$, Anna Bång-Rudenstam¹, Peter Siesjö ${ }^{3,4}$, Anna Ebbesson', Ingrid Hedenfalk1,

Pia C. Sundgren ${ }^{5,6}$, Anna Darabi $^{3}$ and Mattias Belting ${ }^{1,7^{*}}$

\begin{abstract}
Background: Primary brain tumors, in particular glioblastoma (GBM), remain among the most challenging cancers. Like most malignant tumors, GBM is characterized by hypoxic stress that triggers paracrine, adaptive responses, such as angiogenesis and macrophage recruitment, rescuing cancer cells from metabolic catastrophe and conventional oncological treatments. The unmet need of strategies to efficiently target tumor "stressness" represents a strong clinical motivation to better understand the underlying mechanisms of stress adaptation. Here, we have investigated how lipid loading may be involved in the paracrine crosstalk between cancer cells and the stromal compartment of the hypoxic tumor microenvironment.

Methods: Regions from patient GBM tumors with or without the lipid loaded phenotype were isolated by laser capture microdissection and subjected to comparative gene expression analysis in parallel with cultured GBM cells with or without lipid loading. The potential involvement of extracellular lipids in the paracrine crosstalk with stromal cells was studied by immunoprofiling of the secretome and functional studies in vitro as well as in various orthotopic GBM mouse models, including hyperlipidemic ApoE-/- mice. Statistical analyses of quantitative experimental methodologies were performed using unpaired Student's T test. For survival analyses of mouse experiments, log-rank test was used, whereas Kaplan-Meier was performed to analyze patient survival.

Results: We show that the lipid loaded niche of GBM patient tumors exhibits an amplified hypoxic response and that the acquisition of extracellular lipids by GBM cells can reinforce paracrine activation of stromal cells and immune cells. At the functional level, we show that lipid loading augments the secretion of e.g. VEGF and HGF, and may potentiate the cross-activation of endothelial cells and macrophages. In line with these data, in vivo studies suggest that combined local tumor lipid loading and systemic hyperlipidemia of ApoE-/- mice receiving a high fat diet induces tumor vascularization and macrophage recruitment, and was shown to significantly decrease animal survival. (Continued on next page)
\end{abstract}

\footnotetext{
*Correspondence: Mattias.Belting@med.lu.se

†'Svenja Offer, Julien A. Menard and Julio Enríquez Pérez contributed equally to this work.

'Department of Clinical Sciences Lund, Section of Oncology and Pathology, Lund University, Barngatan 4, SE-221 85 Lund, Sweden

${ }^{7}$ Department of Hematology, Oncology and Radiophysics, Skåne University

Hospital, Lund, Sweden

Full list of author information is available at the end of the article
}

(c) The Author(s). 2019, corrected publication 2023. Open Access This article is distributed under the terms of the Creative Commons Attribution 4.0 International License (http://creativecommons.org/licenses/by/4.0/), which permits unrestricted use, distribution, and reproduction in any medium, provided you give appropriate credit to the original author(s) and the source, provide a link to the Creative Commons license, and indicate if changes were made. The Creative Commons Public Domain Dedication waiver (http://creativecommons.org/publicdomain/zero/1.0/) applies to the data made available in this article, unless otherwise stated. 
(Continued from previous page)

Conclusions: Together, these data identify extracellular lipid loading as a potentially targetable modulator of the paracrine adaptive response in the hypoxic tumor niche and suggest the contribution of the distinct lipid loaded phenotype in shaping the glioma microenvironment.

Keywords: Glioma, Lipid metabolism, Hypoxia, Angiogenesis, Macrophages

\section{Background}

High-grade glial tumors (glioblastoma, GBM) are the most common and aggressive primary brain tumors in adults with a poor median overall survival of less than 1 $1 / 2$ years $[1,2]$. GBM, like most other malignant tumors, is characterized by hypoxic stress and extracellular acidification that trigger adaptive responses rescuing cancer cells from metabolic catastrophe and the cytotoxic effect of conventional oncological treatments with cytostatic drugs and ionizing radiation [3, 4]. Oncogenic signaling and GBM stressness have recently been linked to the dependence on lipids rather than glucose as a primary substrate for energy production $[5,6]$. MR imaging studies in patient tumors reported that elevated lipid resonances are a characteristic of hypoxic tumor areas [7], and stressed cancer cells have shown increased de novo lipogenesis as well as extracellular lipid uptake ultimately resulting in lipid droplet (LD) formation and storage [4, 8-11].

Extracellular lipids and their storage into LDs thus emerges as an important, stress-adaptive mechanism in malignant tumors, and recent studies suggest that cancer cells assemble LDs to oxidize fatty acids for increased reductive potential and to rescue cells from oxidative stress $[12,13]$. These studies have revealed an intrinsic role of LDs in energy homeostasis and scavenging of reactive oxygen species in cancer cells. However, the development and progression of malignant tumors depend on paracrine mechanisms to create a hypervascularized and immunosuppressive environment by e.g. increased angiogenesis and macrophage infiltration. Although an association between the abundance of LDs in cancer cells and tumor aggressiveness has been reported for several tumor types, including GBM [14] and prostate cancer [15], the underlying mechanisms of how extracellular lipids and LD storage may contribute to hypoxic signaling and activation of stromal cells to shape the stressed tumor niche remain unknown.

Here, we were interested in investigating how the LD phenotype at the mechanistic and functional level may be involved as a driver of the paracrine crosstalk between cancer cells and the stromal compartment of the hypoxic microenvironment of gliomas.

\section{Methods}

\section{Clinical samples}

Tumor biopsy specimens were obtained from patients with GBM (WHO grade IV) at the Department of
Neurosurgery, Skåne University Hospital, Lund, Sweden. Tumor samples were collected with informed consent according to Protocol H15642/2008 approved by the Lund University Regional Ethics Board, Sweden. Patient plasma samples were from a population-based trial cohort ("MRI study") encompassing patients referred to the Neurosurgery Department at Lund University Hospital, Lund, with a suspicion of an intracranial tumor [16]. The study was carried out according to the $\mathrm{ICH} /$ GCP guidelines and in agreement with the Helsinki declaration, and was approved by the local ethics committee, Lund University (Dnr.2011/814, and 2012/188). Patients were diagnosed by routine MRI of the brain, surgical and pathological procedures, received standard oncological treatment and were followed up according to national recommendations. Blood samples from patients at baseline (pre-operative) and healthy control donors were collected in EDTA tubes, centrifuged at $2000 \mathrm{x} \mathrm{g}$ for $10 \mathrm{~min}$ at room temperature (RT) and plasma was stored at $-80^{\circ} \mathrm{C}$.

\section{Animal studies}

Experimental procedures were approved by the ethical committee for animal research in Malmö/Lund (ethical permit M144-14 and M145-14) and were performed in accordance with the European Union animal rights and ethics directives. Apolipoprotein $\mathrm{E}$ knock out $\left(\mathrm{ApoE}^{-/-}\right)$ mice were fed with high fat diet (21\% fat) (R638, Lantmännen, Sweden) starting 4 weeks prior to cell injection. To obtain GL261 mouse glioma cells with and without LDs, cells were seeded in DMEM containing 10\% FBS overnight $(\mathrm{O} / \mathrm{N})$, washed twice in PBS and incubated in hypoxia in serum-free (SF) medium in the presence or absence of low density lipoprotein (LDL, $50 \mu \mathrm{g} / \mathrm{mL}$ ) for $48 \mathrm{~h}$. Cells were kept subconfluent, detached in trypsin-EDTA, and allowed to recover in DMEM with $10 \%$ FBS for 20 min during counting/viability measurements. The cells were then washed twice and finally resuspended in SF DMEM without antibiotics. For orthotopic injections, 8-12 weeks old NOD/SCID (Taconic Biosciences), C57BL/6, or $\mathrm{ApoE}^{-/-}$mice (The Jackson Laboratory, JAX) were anaesthetized with isoflurane and placed on a stereotactic frame. Mice received Visco-tears and local anesthetic s.c. (Marcaine), a hole was drilled in the skull and $5 \mu \mathrm{L}$ of the cell suspension (50.000 or 100.000 cells, as indicated in the respective 
figure legend) was slowly injected over $2-3 \mathrm{~min} 1.5 \mathrm{~mm}$ to the right and $1.0 \mathrm{~mm}$ anterior of bregma, $2.5 \mathrm{~mm}$ deep from the dural surface using a Hamilton syringe. The needle was left in place for $2 \mathrm{~min}$, and slowly retracted before the skull hole was filled with bone wax and the wound closed with clips. Mice finally received Temgesic analgesic $(0.3 \mathrm{mg} / \mathrm{mL})$ s.c. in the posterior leg. Mice were monitored daily and sacrificed at the indicated time-points or whenever displaying symptoms of distress. The mice brains were then collected and snap-frozen in isopentane before storage at $-80{ }^{\circ} \mathrm{C}$ and sectioning for histological analyses.

\section{Cell-lines}

GBM U-87 MG (newly purchased from ATCC) and GL261 cells were routinely cultured in high-glucose DMEM (HyClone, GE) medium supplemented with 10\% (v/v) FBS (Sigma Aldrich, F7524), $2 \mathrm{mmol} / \mathrm{L}$ L-glutamine (Sigma Aldrich, G7513), $100 \mathrm{U} / \mathrm{ml}$ penicillin, and $100 \mu \mathrm{g} / \mathrm{ml}$ streptomycin (PEST; Sigma Aldrich, P0781). HBMECs were cultured in EC medium (3H Biomedical) supplemented with 5\% (v/v) FBS, 1\% (v/v) EC growth supplement and $1 \%(\mathrm{v} / \mathrm{v})$ PEST. HBMECs at passages 25 were used for experiments. THP-1 cells were maintained in RPMI 1640 medium (HyClone) containing 10\% (v/v) FBS, $2 \mathrm{mmol} / \mathrm{L}$ L-glutamine and 1\% (v/v) PEST. The differentiation of THP-1 cells to a macrophage-like state was induced by adding $50 \mathrm{nM}$ phorbol-12-myristate-13-acetate (PMA, Sigma Aldrich) for $48 \mathrm{~h}$, followed by $48 \mathrm{~h}$ recovery in SF medium in the absence of PMA. All cells were grown in a humidified $5 \% \mathrm{CO}_{2}$ incubator at $37^{\circ} \mathrm{C}$. For hypoxia experiments, cells were incubated in a humidified Sci-tive-NN-Hypoxia workstation (Ruskinn Technology) set at $5 \% \mathrm{CO}_{2}, 94 \% \mathrm{~N}_{2}, 1 \% \mathrm{O}_{2}$, and $37^{\circ} \mathrm{C}$. All hypoxia experiments were performed at SF conditions unless stated otherwise.

\section{Laser microdissection and gene expression}

Human GBM tumor cryosections $(10 \mu \mathrm{m})$ were mounted onto DNase and RNase free membranes (FrameSlide PET), rapidly stained for nuclei using Cresyl Violet (Ambion) and dehydrated in ice-cold ethanol. Slides were stored in sterile $50 \mathrm{ml}$ tubes at $-80^{\circ} \mathrm{C}$ before Laser Capture Microdissection (LCM) using the PALM system from Zeiss. To identify areas of interest, adjacent sections were mounted onto poly-lysine coated slides, fixed with $70 \%(\mathrm{v} / \mathrm{v})$ ethanol for $1 \mathrm{~min}$, stained for nuclei (DAPI) and LDs using HCS LipidToxTM green neutral lipid stain (Life Technologies). Dissected, LD-loaded and non-LD-loaded tumor areas $(N=5$ patients with a total area of approximately $10 \mathrm{~mm}^{2}$ ) were dissolved in $50 \mu \mathrm{l}$ lysis solution provided with AllPrep DNA/RNA Mini Kit (Qiagen), and RNA isolation was performed according to the manufacturer's instructions. RNA concentration and purity were determined with the BioAnalyzer, and quantified using the Affymetrix Clariom D Pico Gene Array at the BEA core facility, Karolinska Institute, Stockholm. Background correction, normalization and annotation were performed with $\mathrm{R}$ statistical language within Rstudio environment (www.r-project.org and https://www.rstudio.com/) with the packages affycoretools, oligo, clariomdhumanprobeset.db and pd.clariom.d.human, all available in the Bioconductor repository (https://www.bioconductor.org/). Further analyses were performed on genes considered as differentially upregulated (cutoff of $0.5 \log _{2} \mathrm{FC}$ ) for $\mathrm{TC}^{\mathrm{LD}+}$ vs $\mathrm{TC}^{\mathrm{LD}-}$ comparison also in $\mathrm{R}$.

\section{Gene expression array and data processing}

U-87 MG cells were grown in SF DMEM for $48 \mathrm{~h}$ in normoxia $(\mathrm{N})$, hypoxia $(\mathrm{H})$, or $\mathrm{H}+\mathrm{LDL}$ (AlfaAesar/ ThermoFisher, $50 \mu \mathrm{g} / \mathrm{mL}$ ). For cell reoxygenation experiments, cells were grown for $48 \mathrm{~h} \mathrm{H}$ or H + LDL $(50 \mu \mathrm{g} /$ $\mathrm{mL}$ ) followed by $1 \mathrm{M} \mathrm{NaCl}$ wash, two PBS washes and two DMEM washes (to remove remaining LDL in cell culture), before another incubation period of $6 \mathrm{~h}$ or $48 \mathrm{~h}$ reoxygenation in $\mathrm{N}\left(20 \% \mathrm{O}_{2}\right)$ in SF DMEM. U-87 MG $\mathrm{NA}$ and AA cells were grown in SF DMEM for $48 \mathrm{~h}$ in $\mathrm{pH} 7.4$ or 6.7. Independent, triplicate experiments were performed for all conditions. Total RNA was extracted using RNAeasy mini kit (Qiagen). Further processing and QC by Bioanalyzer were performed at the SCIBLU Genomics Centre at Lund University for hybridization on HumanHT-12v4 Expression Illumina BeadChip. Downstream background correction, normalization, annotation and differential expression analysis were performed with $\mathrm{R}$ statistical programming language within Rstudio environment, using limma package, available at the Bioconductor repository. Subsequent level 4 GO annotation for cellular component and biological processes analyses were performed with Over-representation Analysis tool available at ConsensusPathDB-Human (http:// cpdb.molgen.mpg.de), with $p$-value cutoffs at 0.01 . Plots on the scrutiny of differentially expressed genes ( $p$-value $<0.01)$ and on pathway analysis results were made with graphical packages for $\mathrm{R}$ environment, such as pheatmap, RColorBrewer and ggplot2, all available at CRAN repository (https://cran.r-project.org/web/packages/).

\section{Multiplex proximity extension assay and ELISA}

U-87 MG cells were treated at the different conditions as indicated above for gene array analyses. Conditioned medium $(\mathrm{CM})$ was collected and spun twice at $300 \times \mathrm{g}$ for $5 \mathrm{~min}$ to remove cell debris, freeze-dried and resuspended in PBS before BCA protein quantification. Secreted proteins in CM as well as in GBM patient and healthy control plasma were analyzed using the Proseek Multiplex Oncology II $^{96 \times 96}$ and CVD III $^{96 \times 96}$ panels 
(Olink Bioscience), as previously described [16-18]. Briefly, the protein quantification is based on proximity extension assay (PEA) technology, which provides high sensitivity and specificity based on the binding of oligonucleotide-labelled antibody probe pairs to their specific target protein, generating a PCR-amplified DNA template, which is proportional to the initial antigen concentration as quantified by real-time qPCR. Four internal and three negative controls were used to calculate the lower limit of detection for each protein. For each analyte/protein detected, difference of normalized protein expression (NPX, log2) between samples was calculated, and linear fold change was obtained with the formula: linear fold change $=2^{\mathrm{NPX}}$.

Validation of some identified proteins (VEGF-A and HGF) was performed using human HGF and VEGF-A Quantikine ELISA assays (R\&D systems) according to manufacturer's instructions. The absorbance was measured at $450 \mathrm{~nm}$ and $540 \mathrm{~nm}$ in a spectrophotometer (FLUOstarOPTIMA).

\section{Western blotting}

Cells were lysed in RIPA buffer $(10 \mathrm{mM}$ Tris- $\mathrm{HCl} \mathrm{pH}$ 7.4, $150 \mathrm{mM} \mathrm{NaCl}, 1 \mathrm{mM}$ EDTA, $0.1 \%$ SDS, $1 \%$ Triton $\mathrm{X}-100,1 \%$ sodium deoxycholate) supplemented with Complete protease inhibitor (Roche Diagnostics). Lysates were centrifuged at $18000 \times g$ for $10 \mathrm{~min}$, and supernatants were stored in $-20^{\circ} \mathrm{C}$ prior to analysis. Protein concentration was measured by BCA assay. For analysis of CM from U-87 MG cells, debris was removed by centrifugation, and supernatants were freeze-dried and resuspended in RIPA buffer with Complete protease inhibitor for analysis. Equal amounts of total protein (or equal volumes for CM samples) were mixed with LDS sample buffer and reducing agent and separated by electrophoresis in a 4-12\% NuPAGE Bis-Tris gel with SeeBlue Plus2 (Invitrogen) as molecular mass standard. The proteins were electroblotted to PVDF membranes (Immobilon-FL, Merck Millipore). After blocking in 5\% nonfat milk in TBS-Tween20 (0.1\%) buffer (blocking buffer) for $1 \mathrm{~h}$ at RT, membranes were probed with the indicated primary antibody (anti-CA9 1:400 (BioScience Slovakia, M75)), anti-vimentin 1:2000 (GeneTex; GTX100619), anti-HIF1 $\alpha$ 1:1000 (GeneTex, GTX127309), anti-HIF2 $\alpha$ 1:500 (Abcam, Ab199)) $\mathrm{O} / \mathrm{N}$ at $4{ }^{\circ} \mathrm{C}$ in blocking buffer. The membrane was washed in TBS-Tween 20 and incubated with HRP-conjugated secondary antibody for $1 \mathrm{~h}$, at RT. Signal detection was performed using ECL Western blotting substrate (Pierce) and quantification of the bands by densitometry using Image (NIH).

\section{Phosphokinase array}

Cells $\left(1 \times 10^{6}\right)$ were seeded in T-25 $\mathrm{cm}^{2}$ flasks, starved in SF DMEM medium $\mathrm{O} / \mathrm{N}$ at $\mathrm{N}$ or $\mathrm{H}$, and stimulated or not with LDL $(50 \mu \mathrm{g} / \mathrm{ml})$ for $5,15,30,45,60$ or $90 \mathrm{~min}$. Cells were lysed in RIPA buffer supplemented with Protease Inhibitor Mixture tablets and phosphatase inhibitors (PhosSTOP, Roche). Total protein from short treatments $(5,15,30 \mathrm{~min})$ and longer treatments $(45,60$, and $90 \mathrm{~min}$ ) were equally mixed and $300 \mu \mathrm{g}$ was analyzed using the Human P-Kinase Array (R\&D Systems) as indicated by the manufacturer. The spot intensity was analyzed using the Protein Array analyzer for ImageJ and fold change of relative protein levels (normalized to array reference) was calculated.

\section{Cell migration}

HBMECs were starved in SF EC medium (1\% L-Glut, $1 \% \mathrm{PEST}) \mathrm{O} / \mathrm{N}$. Cells $\left(4 \times 10^{4}\right)$ were added in SF media to the top chamber of $8-\mu \mathrm{m}$ pore cell culture inserts (BD Biosciences) placed in a 24-well plate. THP-1 cells were differentiated in the top chamber of $8-\mu \mathrm{m}$ pore cell culture inserts for $48 \mathrm{~h}$, followed by starvation in SF medium for $48 \mathrm{~h}$. Cells were incubated at $37^{\circ} \mathrm{C}$ for $6 \mathrm{~h}$ to allow cell migration toward SF medium, or different CM (diluted 1:5 with SF medium for HBMECS and undiluted for THP-1 cells) collected from U-87 MG and GL261 cells, as indicated in the respective figure legend. Migrated cells attached to bottom membrane were fixed with $4 \%$ paraformaldehyde (PFA) for 15 min, stained with crystal violet, and counted from pictures taken under the microscope (Axiovert 40C, $4 \times$ objective; Carl Zeiss).

\section{Matrigel tube formation}

HBMECs were pre-treated with the different CM derived from U-87 MG cells for $24 \mathrm{~h}$ and were then seeded into a growth factor-reduced BD Matrigel (BD Bioscience) pre-coated 96-well plate at $2 \times 10^{4}$ cells per well in EC medium supplemented with 5\% (v/v) FBS and EC growth supplement. EC tube formation was captured 20 $\mathrm{h}$ after seeding (Axiovert 40C microscope, $4 \times$ objective; Carl Zeiss). The angiogenic property was assessed by counting the number of tubes per condition.

\section{Cell proliferation}

HBMECS were seeded $\left(1 \times 10^{3}\right.$ cells $)$ in a 96-well plate and starved in SF medium O/N. Cells were incubated in SF medium or in different CM of U-87 MG or GL261 cells for a total of $72 \mathrm{~h}$. During the last $3 \mathrm{~h}$, cells were cultured in the presence of $20 \mu \mathrm{l} /$ well MTS Reagent (Abcam). The quantification of metabolically active cells was performed by measuring the absorbance at $490 \mathrm{~nm}$.

\section{Immunohistochemistry}

Sections $(6 \mu \mathrm{m})$ were prepared from mouse brains snap frozen in isopentane. H\&E stainings were performed on a Leica ST4020 stainer on every 3rd adjacent sections for morphological analysis and for largest tumor 
diameter measurement. Pictures were captured with an Olympus BX53 microscope or MiraxMidi Zeiss slide scanner for whole slide images. Tumor areas from whole slide pictures were then measured with ImageJ.

\section{Immunofluorescence}

Mouse brain tumor cryosections $(6 \mu \mathrm{m})$ were washed/ rehydrated in PBS for $5 \mathrm{~min}$, fixed in $4 \%$ PFA and washed twice in PBS before blocking with 5\% normal goat serum in PBS (blocking solution) for $1 \mathrm{~h}$, at RT. Primary antibodies (F4/80, 1:10 (Biorad, CI:A3-1); $\alpha$ SMA, 1:100 (Abcam, Ab5694); vWF, 1:100 (Abcam, Ab11713) were then added in blocking solution and incubated $\mathrm{O} /$ $\mathrm{N}$ at $4{ }^{\circ} \mathrm{C}$. Sections were washed, followed by incubation with secondary anti-IgG fluorescent antibodies AF594-donkey anti-rat, 1:200; AF488-goat anti-rabbit, 1:200; and AF594-donkey anti-sheep, 1:200, respectively, for $1 \mathrm{~h}$, at RT. Secondary antibody alone was performed as controls. Nuclei were counter-stained with DAPI. Sections were washed and mounted with fluorescent mounting medium, and slides were observed on an Olympus BX53 fluorescence microscope and pictures captured for quantification. Fluorescence area was quantified using ImageJ on single channel pictures and normalized to the corresponding nuclei area of the same field. The number of fields used for quantification is indicated in the corresponding figure legends.

LD staining was performed as previously described [8]. Briefly, cells were washed in PBS and fixed with $4 \%$ PFA before staining with HCS Green LipidTox staining and Hoechst 33342, washed again in PBS and observed under Zeiss LSM710 confocal microscope using a Plan-Apochromat 63x/1.4 Oil DIC M27 objective.

\section{Statistical analyses}

Statistical analyses of quantitative experimental methodologies were performed using unpaired Student's T test with the GraphPad prism suite (La Jolla, CA, USA). Data is presented as means $\pm \mathrm{SD}$. For survival analyses of mouse experiments, log-rank test was used, whereas Kaplan Meier was performed to produce survival curves from the TCGA patient data. Statistical significance was set at $\alpha=0.05$ level unless otherwise indicated. Empirical Bayes statistics was used to calculate log-odds ratio, moderate f-statistics and moderate t-statistics for microarray data within $\mathrm{R}$ environment. Heatmaps were clustered according to Ward's minimum variance method.

\section{Results}

Lipid loading associates with enhanced hypoxic paracrine signaling in patient GBM

In agreement with previous studies [16], GBM cells grown in normoxia, hypoxia, or normoxia in the presence of extracellular lipid (+LDL) did not display lipid droplets (LDs), whereas hypoxic cells provided with LDL acquired the lipid loaded phenotype (Fig. 1a). Accordingly, GBM patient tumors showed areas with and without LDs, and LD-positive cells resided in the hypoxic tumor niche, as indicated by co-staining for the hypoxia marker GLUT-1 ((Fig. 1b). To gain a better understanding of the nature of GBM patient tumor cells with the lipid loaded phenotype, we comprehensively profiled tumor cell $\mathrm{LD}$ positive $\left(\mathrm{TC}^{\mathrm{LD}+}\right)$ and $\mathrm{LD}$ negative $\left(\mathrm{TC}^{\mathrm{LD}-}\right)$ regions captured from GBM tumors by laser capture microdissection (LCM). In parallel, $\mathrm{TC}^{\mathrm{LD}+}$ and $\mathrm{TC}^{\mathrm{LD}-}$ from human GBM in vitro cultures were profiled for comparative gene array analysis using the most wellcharacterized glioma cell-line, U-87 MG [19] (Fig. 1c). We identified 474 genes that were upregulated in $\mathrm{LD}^{+}$vs $\mathrm{LD}^{-} \mathrm{GBM}$ cells and expressed in patient samples, out of which 430 genes were also increased in $\mathrm{TC}^{\mathrm{LD}+}$ vs $\mathrm{TC}^{\mathrm{LD}-}$ GBM tumor areas (Fig. 1d). Gene ontology (GO) annotation of the 430 commonly upregulated genes revealed the activation of several pathways related to intrinsic cellular biological processes in $\mathrm{TC}^{\mathrm{LD}+}$, but also to paracrine pro-tumorigenic processes, most notably angiogenesis and exosomes (Fig. 1e and f). Also, components of ER, caveolae, and membrane rafts involved in lipid metabolism and LD formation were significantly enriched (Fig. 1f). Among the commonly upregulated $\mathrm{LD}^{+}$associated genes in GBM cells and patient tumors, we found several hypoxia-related, key effectors of angiogenesis, macrophage recruitment and stromal remodeling in cancer (e.g. VEGF-A, TGF- $\beta 1, I L 1 \beta, A D M$, IGFB3, LOX, CA9, THBS1, PLODs, ID2) (Fig. 1g). To specifically elucidate how the hypoxic response may be modulated by LD loading, we next filtered for hypoxia-induced genes (Additional file 1A; Hypoxia vs Normoxia) that were further induced under LD permissive conditions (Additional file 1B; Hypoxia + LDL vs Hypoxia). This identified 22 hypoxia induced genes that were further increased by LD loading in vitro and in $\mathrm{TC}^{\mathrm{LD}+}$ vs $\mathrm{TC}^{\mathrm{LD}-}$ areas from patient tumors (Additional file $1 C$ ). Given that aggressive tumors, including GBM, follow dynamic cycles of hypoxia and reoxygenation as a result of variations in perfusion [20], we next filtered for LD-induced genes after periods of short $(6 h)$ and long-term $(48 \mathrm{~h})$ reoxygenation (Additional file $2 \mathrm{~A}$ and $\mathrm{B}$ ). The results suggested that LD-dependent potentiation of the hypoxic response was largely maintained also in the post-hypoxic phase (Additional file $2 \mathrm{C}$ and $\mathrm{D}$ ).

\section{Lipid loading augments hypoxia mediated secretion of pro-tumorigenic factors}

The above findings prompted further elucidation of how extracellular lipid recruitment and LD formation could be mechanistically and functionally linked to paracrine signaling as an essential part of the hypoxic 
A
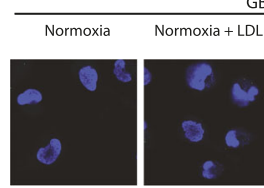

GBM Cells

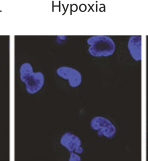

C

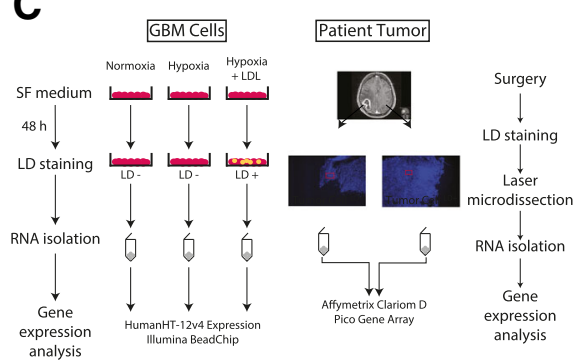

B

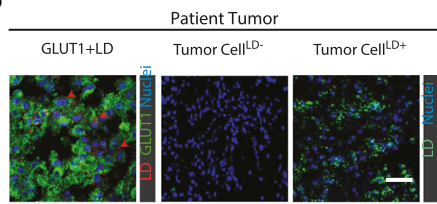

D
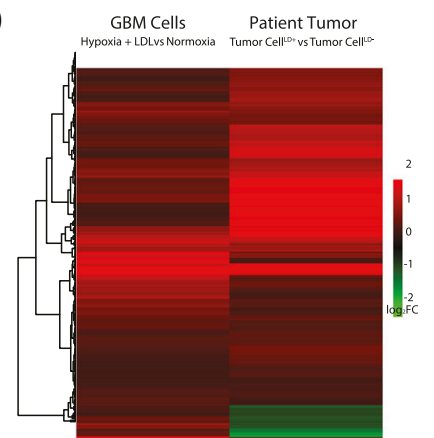

F
E

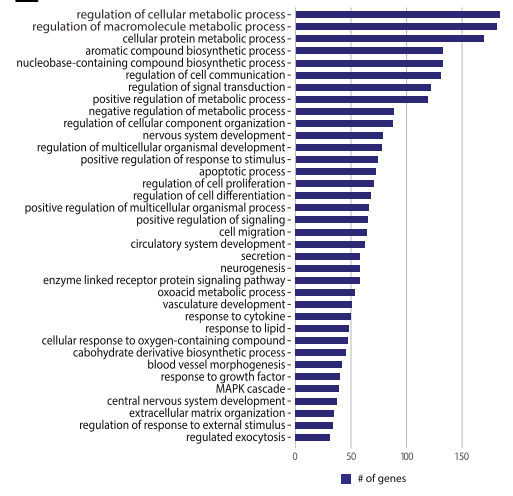

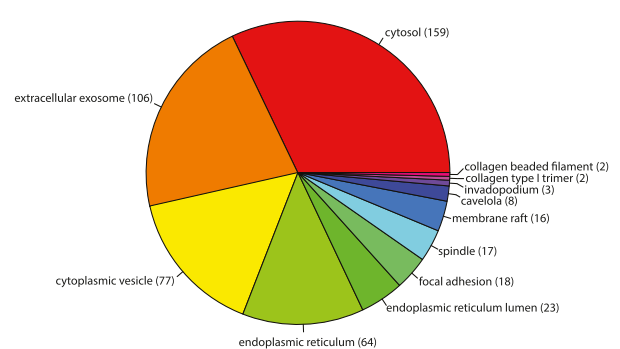

G.

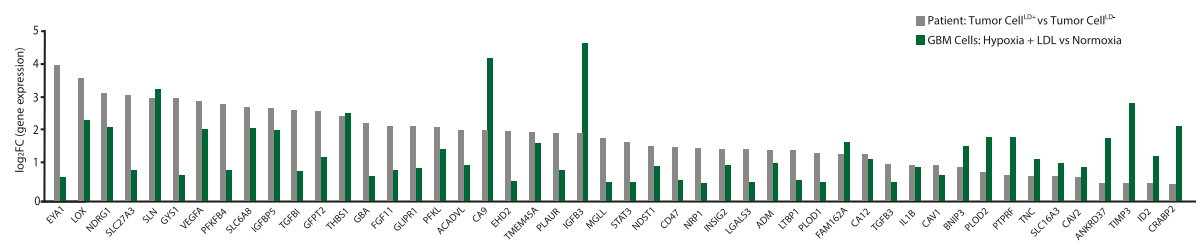

Fig. 1 Comparative gene expression profiling of the LD+ phenotype in GBM patient tumors and cells. a, GBM cells (U-87 MG) were incubated in serum-free medium at normoxic and hypoxic $\left(1 \% \mathrm{O}_{2}\right)$ conditions for $48 \mathrm{~h}$ without or with extracellular lipid (LDL, $\left.50 \mathrm{\mu g} / \mathrm{ml}\right)$ and analyzed for $\mathrm{LDs}$ by confocal microscopy; blue, Hoechst nuclear stain; green: LipidTox LD stain. Shown are representative images of at least three independent experiments. Scale bar, 20 um. b. Immunofluorescence images of GBM patient tumors. Left panel (GLUT1 + LD) shows co-localization of the hypoxia marker GLUT1 (green) and LDs (Nile red; indicated by red arrowheads). Mid (Tumor Cell ${ }^{\mathrm{LD}-}$ ) and right (Tumor Cell ${ }^{\mathrm{LD}+}$ ) panels show typical tumor areas with and without LDs (LipidTox, green). Blue, Hoechst nuclear stain. Scale bar, $100 \mu \mathrm{m}$. c, Schematic overview of the experimental set-up of gene expression analyses. Left: GBM cells ( $\mathrm{U}-87 \mathrm{MG}$ ) were incubated in serum-free (SF) medium at normoxic and hypoxic (1\% $\mathrm{O}_{2}$ ) conditions for $48 \mathrm{~h}$ with no addition of extracellular lipid or in hypoxia with extracellular lipid (LDL, $50 \mathrm{\mu g} / \mathrm{ml})$, and subsequently analyzed for gene expression with the HumanHT-12v4 Expression Illumina BeadChip ( $N=3$ independent experiments). Right: GBM tumors ( $N=5$ patients) were cryosectioned, and LD-negative (Tumor $\left(\mathrm{ell}^{\mathrm{LD}-}\right.$ ) and LD-positive (Tumor Cell ${ }^{\mathrm{LD}+}$ ) tumor areas $(N=8$ and 10 , respectively) were isolated by laser microdissection for gene expression analysis with Affymetrix Clariom D Pico gene array. $\mathbf{d}$, Heatmap showing the differentially upregulated genes in $L^{+}$(Hypoxia + LDL) vs LD (Normoxia) GBM cells and how the same set of genes are differentially expressed in Tumor Cell ${ }^{L D+}$ vs Tumor Cell ${ }^{\mathrm{LD}-}$ areas from GBM patient tumors. e, Biological processes plot generated from the commonly upregulated genes shown in (d) according to Gene Ontology level 4 annotation, $P<0.01$. f, Cellular component analysis generated as described in (e). g, Significantly upregulated genes of interest in Tumor Cell ${ }^{\mathrm{LD}+}$ vs Tumor Cell ${ }^{\mathrm{LD}-}$ from patient tumors (gray bars) and LD ${ }^{+}$(Hypoxia + LDL) vs LD ${ }^{-}$(Normoxia) GBM cells (green bars). Data in (d) and (g) are presented as $\log _{2}$ of fold-change (FC) 
response. We next employed an ultrasensitive immunoassay based on proximity extension assay (PEA) technology to profile the secreted levels of 184 proteins implicated in cancer-stromal cell crosstalk [16-
18]. In support of the validity of the assay, several proteins encoded by hypoxia-regulated genes were substantially increased in the hypoxic as compared with the normoxic GBM cell secretome (Fig. 2a, light gray

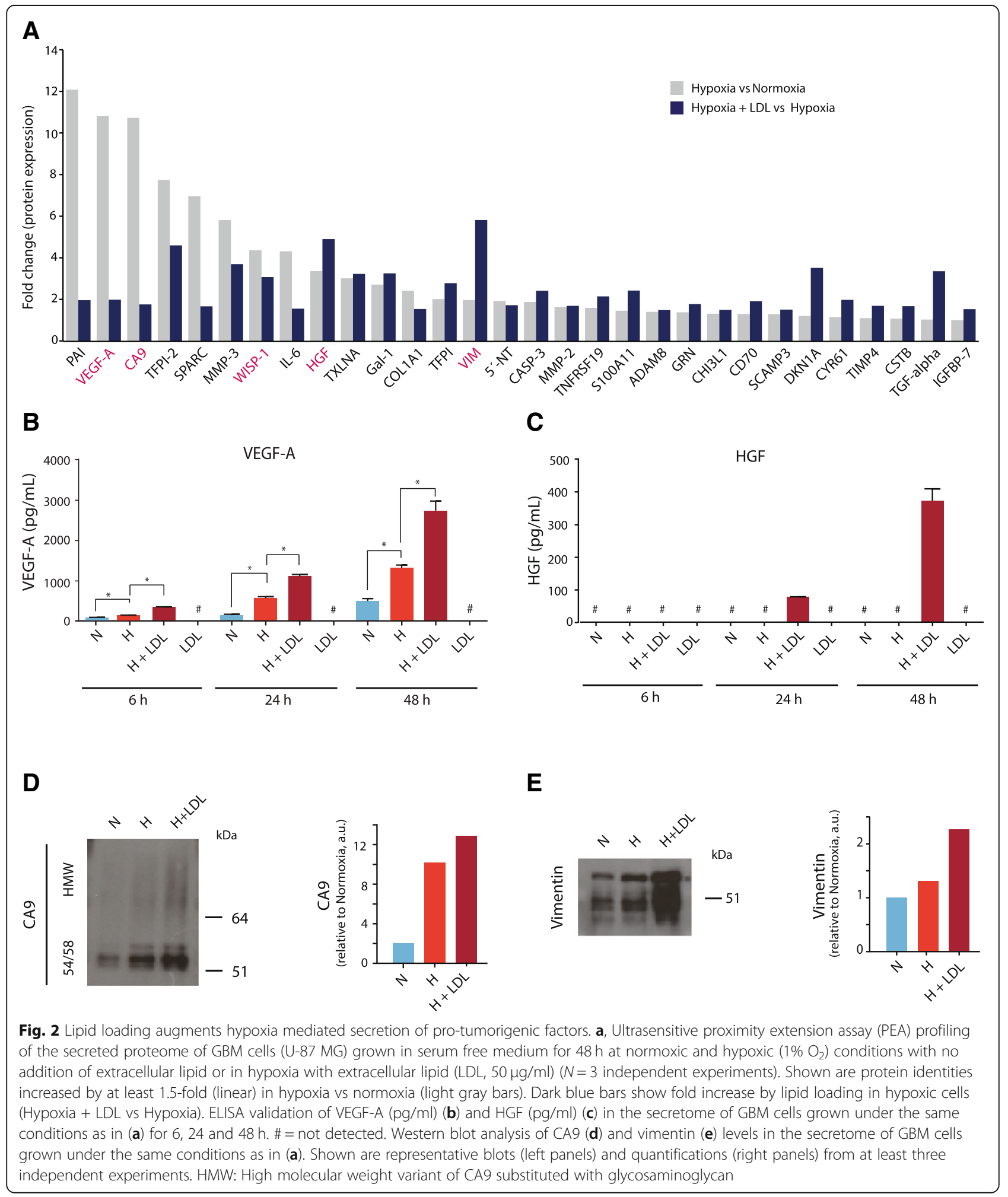


bars). Interestingly, lipid loading was found to augment the hypoxic induction of proteins with key roles in angiogenesis and macrophage recruitment, most importantly VEGF-A (approximately 2-fold) and HGF (approximately 5-fold) (Fig. 2a, dark blue bars). We identified vimentin, i.e. an intermediate filament protein linked to epithelial-to-mesenchymal transition and LD formation [21] as the most highly induced in lipid loading conditions (almost 6-fold as compared with hypoxia only). Several of these responses were maintained also in the reoxygenation phase (Additional file $3 \mathrm{~A}$ and $\mathrm{B}$ ). PEA profiling experiments were corroborated by quantitative ELISA, showing that lipid loading significantly amplified the hypoxic induction of VEGF-A (Fig. 2b). This effect was seen already at 6 $\mathrm{h}$ (2.6-fold) and was maintained at $24 \mathrm{~h}$ and $48 \mathrm{~h}$ (2-fold) of lipid loading (Fig. 2b) and was dependent on the concentration of extracellular lipid (Additional file 3C). Remarkably, ELISA analysis showed detectable HGF levels only under conditions of lipid loading, both during 24 and $48 \mathrm{~h}$ of hypoxia (Fig. 2c), and also this effect was dependent on extracellular lipid concentration (Additional file 3D). As a control, LDL per se was negative for VEGF-A (Fig. 2b) and HGF (Fig. 2c). Additional proteins of interest were validated by immunoblotting, showing that lipid loading potentiated the hypoxic induction of CA9 and vimentin (Fig. $2 \mathrm{~d}$ and e). To explore how these results may be reflected by the circulating secretome of GBM patients, we next performed PEA immunoprofiling of plasma from a GBM patient cohort $(N=68)$ as well as in healthy control subjects $(N=16)$ (Additional file 4A). We found significantly increased levels of VEGF-A, HGF, and vimentin in primary GBM (pre-surgery) as compared with healthy controls, and higher levels of these proteins associated with worse patient outcome (Additional file 4B-D).

Lipid loading-dependent amplification of the hypoxic response appeared independent on hypoxia inducible factors (HIFs), which serve as transcriptional master regulators of the hypoxic signaling program [22, 23], as lipid loading per se had no apparent effect on HIF-1 $\alpha$ and HIF- $2 \alpha$ protein levels, neither in normoxia nor in hypoxia (Fig. 3a and b). However, using an antibody array for phosphokinase activation, we found increased phosphorylation of cyclic AMP-response-element binding protein (CREB) (Fig. 3c and d), which has been widely implicated in stress adaptation, and transcriptional induction of VEGF-A through cooperation with HIF-1 $\alpha$ [24-27]. Corroborating immunoblotting experiments showed that lipid loading transiently increased the phosphorylated fraction of CREB preferentially in hypoxic conditions (Fig. 3e). Together, these results indicate that lipid loading can amplify the hypoxic response in GBM cells and patient tumors, apparently through mechanisms that do not directly depend on increased HIF stabilization.

\section{Tumor cell lipid loading promotes paracrine activation of vascular cells and macrophages}

We next investigated how increased secretion of pro-malignant factors by lipid loading may directly regulate the functional crosstalk with stromal cell components of the GBM tumor microenvironment (Fig. 4a). Based on patient GBM and tumor cell profiling data (Figs. 1 and 2), we initially focused on how the secretome from GBM cells grown under LD permissive (hypoxia + LDL) as compared with non-permissive (normoxia, normoxia + LDL, or hypoxia only) conditions regulates endothelial cell (EC) activity. Interestingly, human brain microvascular EC (HBMEC) migration towards conditioned medium (CM) from hypoxic lipid loaded cells was significantly increased by approximately 1.7 -fold and 1.4-fold as compared with CM from normoxic and hypoxic GBM cells, respectively (Fig. 4b and c). The effect on HBMEC cell proliferation was even greater, showing an almost 2-fold induction by lipid loading (Fig. 4d). We found similar effects on HBMECs with the different CM variants derived from GL261 cells, i.e. a widely used mouse high grade glioma model [28, 29] (Additional file $5 \mathrm{~A}$ and $\mathrm{B}$ ). Also, CM from lipid loaded GBM cells was shown to significantly potentiate HBMEC tube formation (Fig. 4e and f). Moreover, we found that CM from lipid loaded cells as compared with normoxic cells was significantly more potent at stimulating macrophage migration (Fig. 4g and h). Similar results were obtained in experiments with CM derived from GL261 cells (Additional file 5C). Notably, LDL supplementation per se (LDL) had no direct effect on HBMECs or macrophages (dark grey bars in Fig. 4c, d, f, h and Additional file 5A-C). Together, these results suggest that extracellular lipid loading can amplify hypoxia mediated, paracrine activation of ECs and macrophages.

\section{Lipid loaded tumor cells foster increased angiogenesis and macrophage infiltration in glioma}

To explore how these findings may be translated to the in vivo setting, we initially employed GL261 cells for orthotopic injection of cells pre-conditioned in hypoxia without (LD negative, $\mathrm{LD}^{-}$) and with LDL loading (LD positive, $\mathrm{LD}^{+}$), in immunodeficient NOD/SCID mice (Fig. 5a). In this setting, there was a non-significant decrease in animal survival in the $\mathrm{LD}^{+}$as compared with the $\mathrm{LD}^{-}$groups (Fig. 5b; $P=0.141$ ) and tumor area (Fig. $5 \mathrm{c}$ and $\mathrm{d} ; P=0.175)$. Interestingly, immunofluorescence mapping of the tumor microenvironment revealed a significantly increased infiltration of tumor associated 


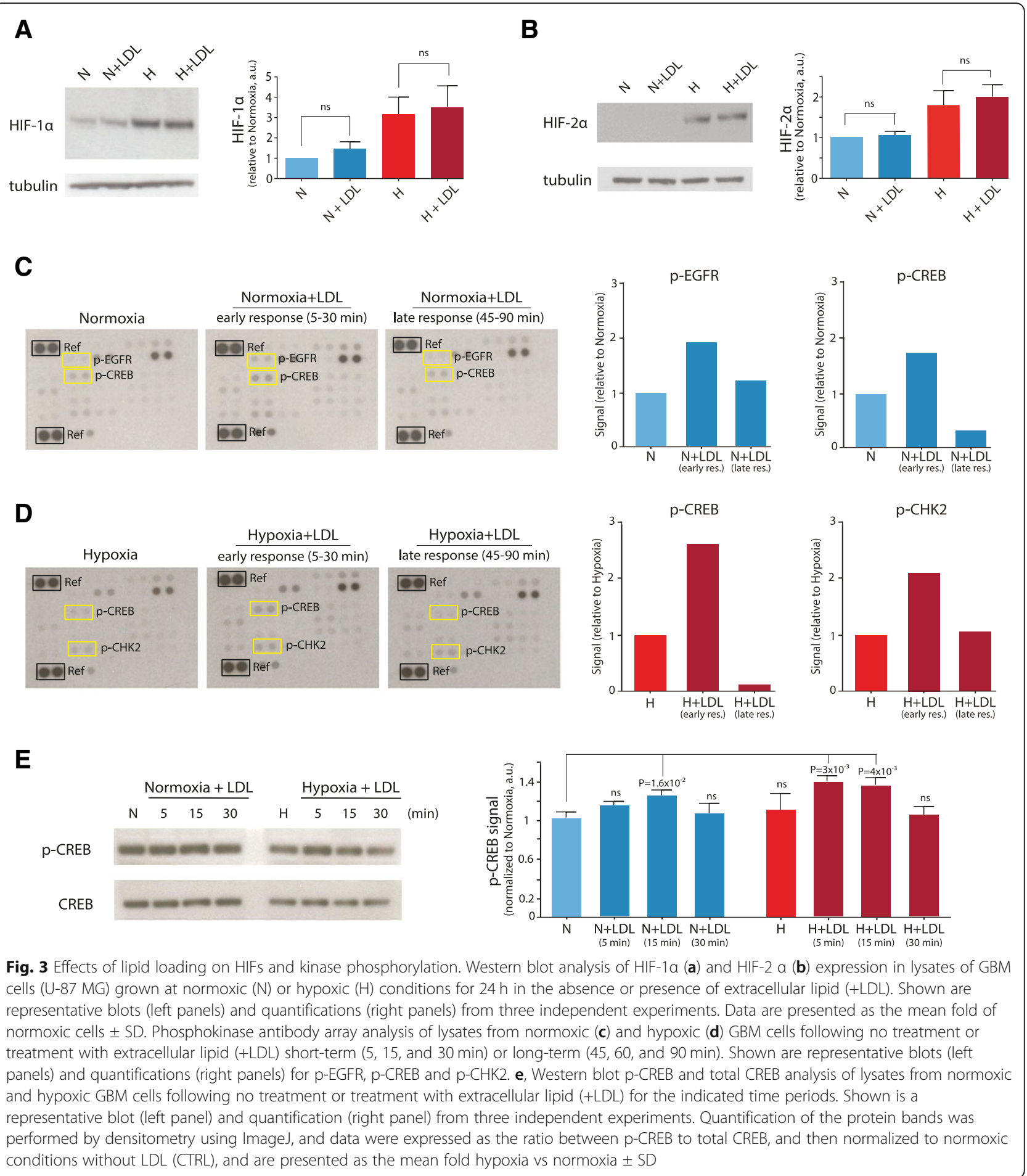

macrophages (TAM) (> 3-fold; $P=0.001$; Fig. 5e and f), and there was a strong trend towards an increased tumor density of $\alpha$ SMA-positive, pericyte like vascular cells in the $\mathrm{LD}^{+}$group (> 3-fold; $P=0.06$; Fig. $5 \mathrm{~g}$ and $\mathrm{h}$ ). Together, these data suggest that GBM cell lipid loading confers an increased angiogenic response and TAM infiltration to gliomas grown in immunodeficient mice.

\section{Hyperlipidemia promotes macrophage infiltration, angiogenesis and GBM aggressiveness}

The above findings motivated further studies on the potential regulatory role of systemic lipids in GBM tumor development, specifically, how hyperlipidemia may regulate angiogenesis and macrophage infiltration in immunocompetent animals. We established the GL261 
A

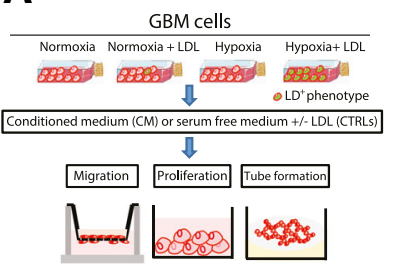

D

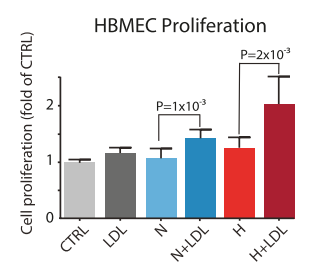

G

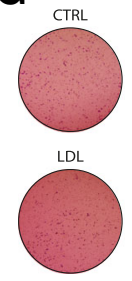

B

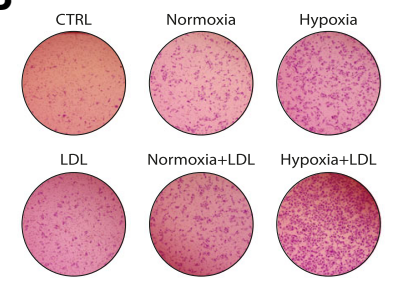

E

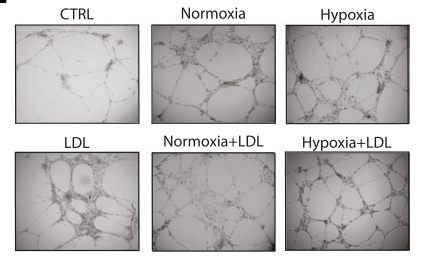

C

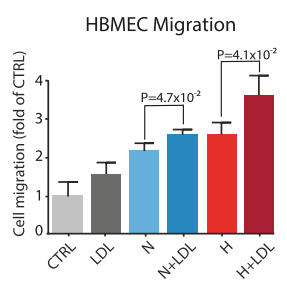

F

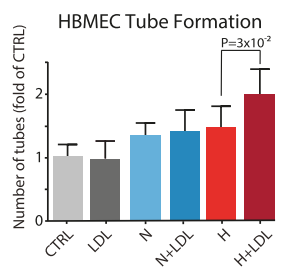

H

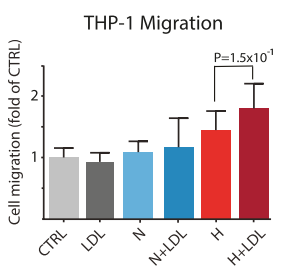

Fig. 4 Tumor cell lipid loading promotes paracrine activation of vascular cells and macrophages. a, Schematic overview of functional assays with conditioned medium (CM) isolated from GBM cells (U-87 MG) grown in serum-free (SF) medium without and with extracellular lipid (+LDL) in normoxia or hypoxia. $\mathbf{b}$ and $\mathbf{c}$, HBMECs were assessed for transwell migration over a period of $6 \mathrm{~h}$ towards SF medium (CTRL) and the various GBM CM variants described in (a). LDL = SF medium supplemented with LDL. Shown are representative images of migrated ECS $(\mathbf{b})$ and quantification (c). d, HBMECs were cultured for $72 \mathrm{~h}$ at the same conditions as described in (b) and assessed for cell proliferation. $\mathbf{e}$ and $\mathbf{f}$, HBMECs were cultured for $24 \mathrm{~h}$ at the same conditions as in (b) and then allowed to form tube structures on Matrigel for $20 \mathrm{~h}$. Shown are representative images of EC tubes from the indicated treatments (e) and quantification of number of tubes (f). $\mathbf{g}$ and $\mathbf{h}$, Human-derived monocytes differentiated into macrophages (THP-1) were assessed for transwell migration over a period of $6 \mathrm{~h}$ towards the same media conditions as described in (b). Shown are representative images of migrated THP-1 cells (g) and quantification (h). b-h Data are presented as the mean fold of untreated $(C T R L) \pm S D$ from at least three independent experiments

model in syngeneic C57BL/6 mice, either wild-type (WT) on chow diet or Apolipoprotein E knock-out mice $\left(\mathrm{ApoE}^{-/-}\right)$that develop severe hyperlipidemia after a few weeks on high fat diet (HFD) [30, 31] (Fig. 6a). Intriguingly, in the hyperlipidemic situation of $\mathrm{ApoE}^{-/-}$mice, orthotopic injection of GL261 LD $\mathrm{LD}^{+}$as compared with GL261 LD LD $^{-}$cells resulted in a significantly decreased survival (Fig. 6b). Moreover, $\mathrm{ApoE}^{-/-}$as compared with WT mice exhibited reduced survival when receiving GL261 LD ${ }^{+}$cells (Fig. 6b), suggesting that combined tumor cell lipid loading and systemic lipid levels has a significant impact on GBM aggressiveness. Consistent with the results from the NOD/SCID model (Fig. 5), TAM infiltration was significantly increased in mice injected with $\mathrm{LD}^{+}$vs $\mathrm{LD}^{-}$cells, both in WT and $\mathrm{ApoE}^{-1-}$ mice (Fig. 6c and d). Interestingly, hyperlipidemia was shown to increase TAMs in mice injected both with $\mathrm{LD}^{+}$ and $\mathrm{LD}^{-}$tumor cells, indicating that initial GBM cell lipid loading and an increased systemic lipid supply had additive effects on TAM infiltration (Fig. $6 \mathrm{c}$ and d). We found similar effects on blood vessel formation, as assessed by staining for $\alpha$ SMA (Fig. 6e and f) and vWF (Fig. $6 \mathrm{~g}$ and $\mathrm{h}$ ), although tumor hypervascularization in systemic hyperlipidemia was not further increased by initial tumor cell lipid loading. Taken together, results from immunodeficient and immunocompetent mouse glioma models (Figs. 5 and 6) provide evidence that lipid levels, both locally in the tumor cells and systemically, can promote angiogenesis, TAM infiltration and GBM tumor aggressiveness.

\section{Discussion}

The current work provides new insights into the role of extracellular lipids and the LD phenotype in the regulation of hypoxia mediated tumor development by an increased angiogenic response and macrophage recruitment. We show that the LD phenotype of patient tumors is associated with an enhanced hypoxic response, and that extracellular lipids can augment hypoxic paracrine signaling by increased secretion of key effector 


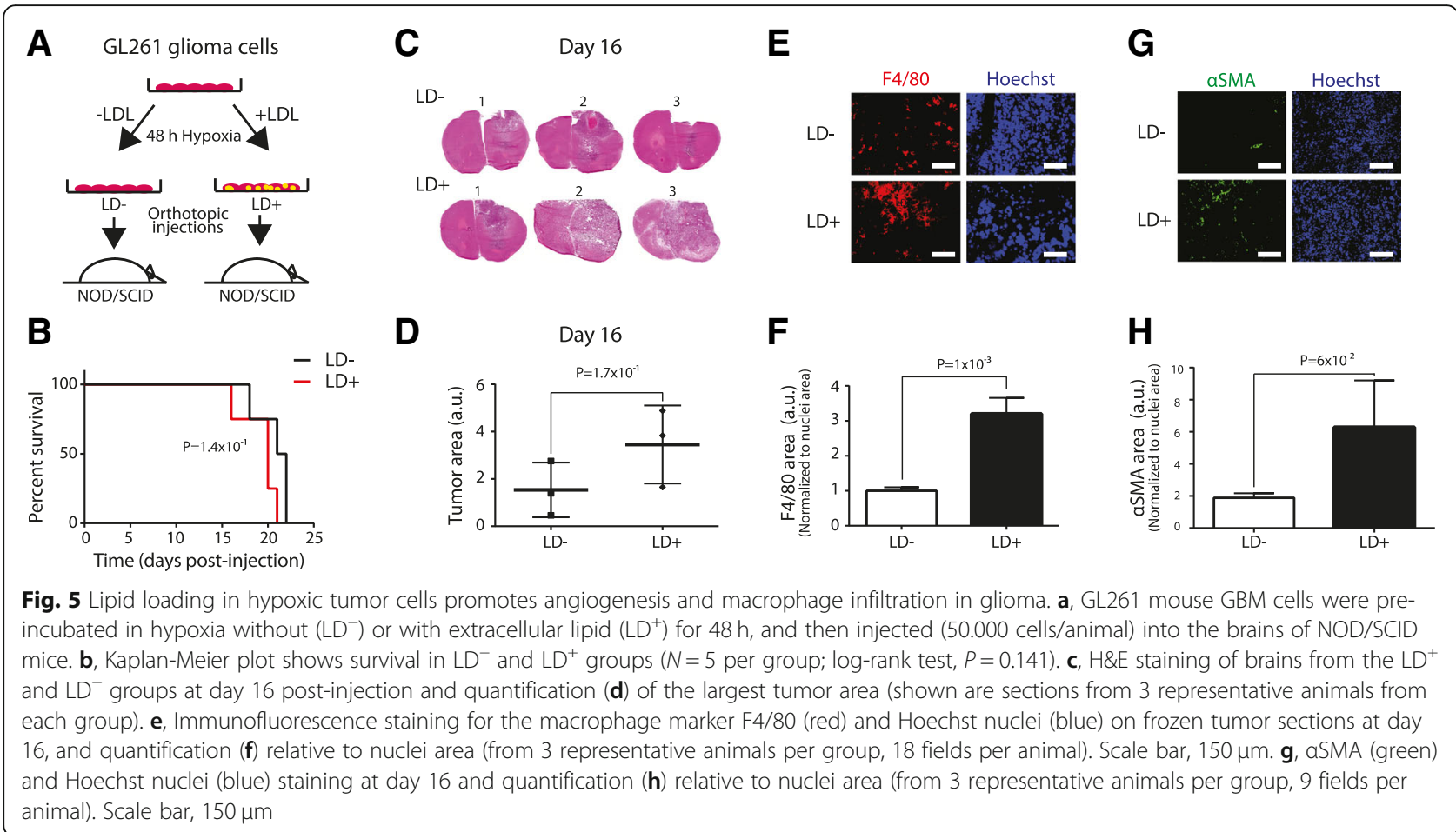

molecules involved in shaping the GBM stromal compartment. Our results reveal a reciprocal crosstalk between hypoxia and lipid loading and underscore the potential synergy between autocrine and paracrine mechanisms during metabolic adaptation to tumor stressness. This should motivate future studies focusing on how the lipoprotein uptake machinery may be targeted as an effective therapeutic approach, especially in notoriously hypoxic GBM tumors.

The correlation of angiogenesis and abundance of macrophages with glioma grade and poor GBM patient outcome is well-documented [32, 33]. Here, we found a substantial increase in TAM infiltration and neovascularization in tumors established from $\mathrm{LD}^{+} \mathrm{GBM}$ cells, and this effect was augmented by an elevated, continuous supply of systemic lipids. Moreover, we show that lipid loading can induce the secretion of major, pro-malignant factors implicated in TAM recruitment and the angiogenic response, i.e. VEGF-A and HGF $[34,35]$. Tumor hypervascularization in systemic hyperlipidemia was not further increased by tumor cell LD loading, i.e. the effects of systemic hyperlipidemia per se on tumor angiogenesis may hide the effects of tumor cell LD loading in this setup. Notably, TAM recruitment with LD+ GBM cells was increased not only in the WT group but also in the hyperlipidemic background, suggesting that in this context the additive effect of systemic lipid levels and tumor cell LD loading on animal survival is mediated through increased macrophage infiltration. TAMs may represent more than half of the GBM tumor mass [35], and previous studies in the GL261 mouse glioma model suggested that the relative contribution of peripheral monocytes and macrophages vs resident microglia progressed over time to more than $1 / 3$ of the total TAM population [36]. TAMs thus constitute a mixed cell population that can promote GBM pathology by immunosuppressive actions but also as a major source of angiogenic growth factors, including VEGF [32]. Accordingly, targeting of TAMs through inhibition of CSF1R increased the survival in experimental GBM [37] and may improve the effectiveness of anti-angiogenic therapies [38]. It is conceivable that the hypervascularized phenotype of lipid loaded tumors, as shown here, is the result of pro-angiogenic signaling directly by malignant cells but also secondary to TAM recruitment.

The leaky vasculature of GBM, and other hypoxic tumors, allows the recruitment of systemic lipids, including free fatty acids with mean concentrations of approximately $50-120 \mathrm{mM}$ in plasma and the considerably more abundant cholesteryl esters (approximately 400$750 \mathrm{mM}$ ) and triglycerides sequestered in lipoproteins [39]. Tumor tissues readily have access to and metabolize circulating lipids, and LDL was shown to transcytose over the endothelial cell barrier [40]. Also, in conditions where the endothelial barrier integrity is compromised, lipoproteins can have direct access deep into tissues [41]. In favor of this notion, the present study shows that HFD/hyperlipidemia can synergize with tumor cell lipid loading to promote GBM tumor 


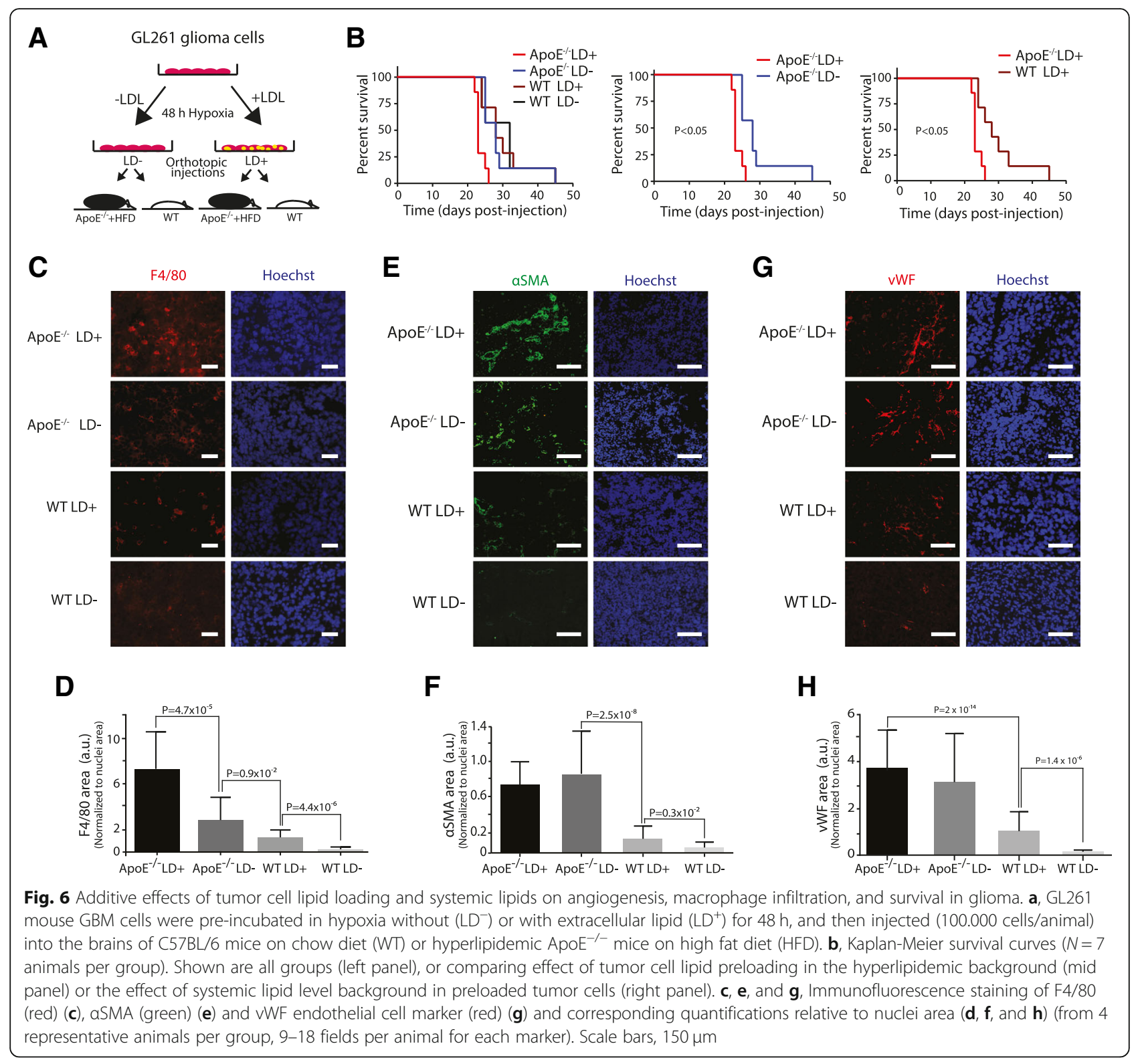

remodeling and aggressiveness, thereby establishing a mechanistic and causal link between lipid accumulation and tumor progression. Obesity is a well-established risk factor in many cancers, including breast and colon cancer, as well as clear cell renal cell carcinoma [42]. How obesity is affecting patients with high-grade glioma is, however, still unclear, but a correlation has been suggested between obesity and an enhanced risk of brain tumors [43, 44-46].

\section{Conclusions}

Our findings high-light the role of lipid metabolism in cancer by revealing an association between cancer cell lipid loading and increased hypoxic stress adaptive paracrine signaling, resulting in augmented cross-activation of major inhabitants of the stressed GBM tumor niche. We conclude that the studied mechanisms represent potentially targetable modulators of the adaptive metabolic response, which should motivate the identification of new drugs or repurposing of drugs from the cardiovascular field targeted at extracellular lipid internalization and LD formation for the treatment of GBM.

\section{Additional files}

Additional file 1: Lipid loading potentiates the hypoxic response in GBM cells and patient tumors. Shown is hypoxic regulation (Hypoxia vs Normoxia) (A) and further amplification of gene expression by lipid loading (Hypoxia + LDL vs Hypoxia) (B) in GBM (U-87 MG) cells. C, Heatmap of differentially expressed genes in GBM cells and patient 
tumors. Column 1: Upregulated genes by hypoxia in GBM cells (Hypoxia vs Normoxia). Column 2: Hypoxia-induced genes further induced by lipid loading in GBM cells (Hypoxia + LDL vs Hypoxia). Column 3: Differential expression of genes presented in Column 1 and 2 for patient Tumor CellLD ${ }^{+}$and Tumor CellLD ${ }^{-}$(Tumor CellLD ${ }^{+}$vs Tumor CellLD ${ }^{-}$) areas isolated by laser microdissection. Bar graph (right panel) highlights the relative expression of commonly upregulated genes in Tumor CellLD ${ }^{+}$vs Tumor CellLD ${ }^{-}$(gray bars) and Hypoxia + LDL vs Normoxia (black bars). Data (A-C) is presented as $\log _{2}$ fold-change (FC). (PDF $36 \mathrm{~kb}$ )

Additional file 2: Maintained effect of lipid loading on gene expression in reoxygenated, post-hypoxic conditions. A, GBM cells (U-87 MG) were grown in hypoxia without $\left(\mathrm{LD}^{-}\right)$and with $\mathrm{LDL}\left(\mathrm{LD}^{+}\right)$and then reoxygenated. Shown are genes induced at least $1.1 \log _{2}$ of fold change (FC) in LD+ vs LD- cells following $6 \mathrm{~h}$ of reoxygenation. B, Same analysis as in (A) at $48 \mathrm{~h}$ of reoxygenation. C, Expression of the commonly upregulated genes in Tumor CellLD ${ }^{+}$vs Tumor CellLD ${ }^{-}$and Hypoxia + LDL vs Hypoxia, as shown in Additional file $1 C$, in $L D^{+}$vs $L D^{-}$cells following $6 \mathrm{~h}$ of reoxygenation. In all cases, there is a maintained induction by lipid loading. D, Same analysis as in (C) at $48 \mathrm{~h}$ of reoxygenation. (PDF $15 \mathrm{~kb}$ )

Additional file 3: Effects of lipid loading on the hypoxic and posthypoxic GBM cell secretome. A and B, Maintained effect of lipid loading on protein secretion in reoxygenated, post-hypoxic conditions: GBM cells ( $(\mathrm{-}-87 \mathrm{MG})$ were grown in hypoxia without $\left(\mathrm{LD}^{-}\right)$and with $\mathrm{LDL}\left(\mathrm{LD}^{+}\right)$and then reoxygenated for $6 \mathrm{~h}(\mathrm{~A})$ and $48 \mathrm{~h}$ (B). Shown is linear fold change $(F C)$ of protein levels in $L D^{+} v s L D^{-}$cells as determined by proximity extension assay. C and D, ELISA quantification of VEGF-A (C) and HGF (D) in the secretome of GBM cells grown in normoxia (N), hypoxia without $L D L(H)$ or in hypoxia with $L D L$ at the indicated concentrations. $L D L=$ LDL only $(50 \mu \mathrm{g} / \mathrm{ml})$. \# = Not detected. (PDF $16 \mathrm{~kb})$

Additional file 4: VEGF-A, HGF, and vimentin are increased in GBM patient plasma and correlate with disease aggressiveness. A, Proximity extension assay (PEA) immunoprofiling of proteins in plasma from GBM patients $(N=68)$ and healthy controls $(N=16)$ shows that several proteins increased by LD loading in vitro (as shown in Fig. 2a) are also increased in GBM patient plasma. Data shown are corrected values (for age and sex) presented as the mean linear fold change. ${ }^{*} P \leq 0.05$. B-D, 1-year survival of GBM patients with high or low expression levels of VEGF-A (B), vimentin (VIM) (C) and HGF (D). (PDF $45 \mathrm{~kb}$ )

Additional file 5: Tumor cell lipid loading promotes paracrine activation of vascular cells and macrophages. See Fig. 4a for a schematic overview of functional assays with conditioned medium (CM) isolated from GBM cells (U-87 MG or GL261) grown in serum-free (SF) medium without and with extracellular lipid (+LDL) in normoxia $(\mathrm{N})$ or hypoxia $(\mathrm{H})$. A, HBMECs were assessed for transwell migration over a period of $6 \mathrm{~h}$ towards SF medium (CTRL) and the various GL261 CM variants, as indicated. $L D L=S F$ medium supplemented with LDL. B, HBMECs were cultured for $72 \mathrm{~h}$ at the same conditions as described in (A) and assessed for cell proliferation. C, Human derived monocytes differentiated into macrophages (THP-1) were assessed for transwell migration over a period of $6 \mathrm{~h}$ towards the same media conditions as described in (A and B). A-C, Data are presented as the mean fold of untreated (CTRL) $\pm S D$ from at least three independent experiments. (PDF $12 \mathrm{~kb}$ )

\section{Abbreviations}

ApoE: Apolipoprotein E; aSMA: Alpha smooth muscle actin; CM: Conditioned medium; CREB: Cyclic AMP-response-element binding protein; GBM: Glioblastoma; H: Hypoxia; HBMEC: Human brain endothelial cells; HFD: High fat diet; HIF: Hypoxia inducible factor; LD: Lipid droplet; LDL: Low density lipoprotein; N: Normoxia; PEA: Proximity extension assay; PFA: Paraformaldehyde; RT: Room temperature; SF: Serum free; TAM: Tumor associated macrophage; TC: Tumor cell; vWF: Von Willebrandt factor; WT: Wild-type

\section{Acknowledgements}

We thank all the patients who participated in the study, and all the investigators and staff who contributed their time and effort. We also thank Anna Weddig, research nurse, for help with the collection and handling of patient samples.

\section{Funding}

The Swedish Cancer Fund CAN 2017/664 and 2016/365 (M.B. and P.C.S.); the Swedish Research Council VR-MH 2014-3421 and K2011-52X-21737-01-3 (M.B. and P.C.S.); the Swedish Childhood Cancer Foundation PR2015-0078 (M.B.); the Fru Berta Kamprad Foundation (M.B.); the Skåne University Hospital donation funds (M.B. and P.S.); the Governmental funding of clinical research within the national health services, ALF (M.B.; P.C.S.; P.S.); and a donation by the Viveca Jeppsson Foundation (M.B.).

The funding sources had no role in the design of the study and collection, analysis, and interpretation of data and in writing the manuscript.

\section{Availability of data and materials}

The gene array datasets generated and/or analysed during the current study will be deposited in the Gene Expression Omnibus (GEO) database, www. ncbi.nlm.nih.gov/geo.

\section{Authors' contributions}

M.B. conceived and supervised the study. A.B.R., A.D., A.E., I.H., J.E., J.A.M., K.G.O., M.B., M.C.J, and S.O. designed and performed the experiments; A.D., P.C.S., and P.S. provided patient samples; A.E., I.H., and M.C.J assisted with data collection; J.E., J.A.M., K.G.O., M.B., S.O., and V.I.C. analyzed the data; M.B., P.C.S., and P.S. provided funding; J.A.M., K.G.O., M.B. and S.O. wrote the paper with input and approval from all the authors.

\section{Ethics approval and consent to participate}

Tumor samples were collected with informed consent according to Protocol H15642/2008 approved by the Lund University Regional Ethics Board, Sweden. Patient plasma samples were from a population-based trial cohort ("MRI study") encompassing patients referred to the Neurosurgery Department at Lund University Hospital, Lund, with a suspicion of an intracranial tumor. The study was carried out according to the ICH/GCP guidelines and in agreement with the Helsinki declaration, and was approved by the local ethics committee, Lund University (Dnr.2011/814, and 2012/188). Animal studies were approved by the ethical committee for animal research in Malmö/Lund (ethical permit M144-14 and M145-14) and were performed in accordance with the European Union animal rights and ethics directives.

\section{Consent for publication}

Not applicable.

\section{Competing interests}

The authors declare that they have no competing interests.

\section{Publisher's Note}

Springer Nature remains neutral with regard to jurisdictional claims in published maps and institutional affiliations.

\section{Author details}

${ }^{1}$ Department of Clinical Sciences Lund, Section of Oncology and Pathology, Lund University, Barngatan 4, SE-221 85 Lund, Sweden. ${ }^{2}$ Center for Translational Cancer Research, Technical University of Munich, Munich, Germany. ${ }^{3}$ Department of Clinical Sciences Lund, Section of Neurosurgery, Lund University, Lund, Sweden. ${ }^{4}$ Department of Neurosurgery, Skåne University Hospital, Lund, Sweden. ${ }^{5}$ Department of Clinical Sciences, Lund, Section of Diagnostic Radiology, Lund University, Lund, Sweden. ${ }^{6}$ Department of Medical Imaging and Function, Skåne University Hospital, Lund, Sweden. ${ }^{7}$ Department of Hematology, Oncology and Radiophysics, Skåne University Hospital, Lund, Sweden.

\section{Received: 4 April 2019 Accepted: 13 May 2019}

\section{Published online: 07 June 2019}

\section{References}

1. Louis DN, Perry A, Reifenberger G, von Deimling A, Figarella-Branger D, Cavenee WK, et al. The 2016 World Health Organization classification of tumors of the central nervous system: a summary. Acta Neuropathol. 2016; 131:803-20.

2. Omuro A. Glioblastoma and other malignant gliomas. JAMA. 2013;310:1842.

3. Quail DF, Joyce JA. Microenvironmental regulation of tumor progression and metastasis. Nat Med. 2013;19:1423-37. 
4. Schulze A, Harris AL. How cancer metabolism is tuned for proliferation and vulnerable to disruption. Nature. 2012;491:364-73.

5. Strickland M, Stoll EA. Metabolic reprogramming in glioma. Front Cell Dev Biol. 2017;5:43.

6. Lin H, Patel S, Affeck VS, Wilson I, Turnbull DM, Joshi AR, et al. Fatty acid oxidation is required for the respiration and proliferation of malignant glioma cells. Neuro-Oncology. 2017;19:43-54.

7. Delikatny EJ, Chawla S, Leung DJ, Poptani H. MR-visible lipids and the tumor microenvironment. NMR Biomed. 2011;24:592-611.

8. Menard JA, Christianson HC, Kucharzewska P, Bourseau-Guilmain E,

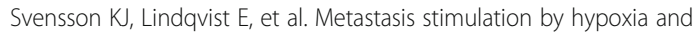
acidosis-induced extracellular lipid uptake is mediated by proteoglycandependent endocytosis. Cancer Res. 2016;76:4828-40.

9. Ackerman D, Simon MC. Hypoxia, lipids, and cancer: surviving the harsh tumor microenvironment. Trends Cell Biol. 2014;24:472-8.

10. Ackerman D, Tumanov S, Qiu B, Michalopoulou E, Spata M, Azzam A, et al. Triglycerides promote lipid homeostasis during hypoxic stress by balancing fatty acid saturation. Cell Rep. 2018;24:2596-605.

11. Furuta E, Pai SK, Zhan R, Bandyopadhyay S, Watabe M, Mo YY, et al. Fatty acid synthase gene is up-regulated by hypoxia via activation of Akt and sterol regulatory element binding Protein-1. Cancer Res. 2008;68:1003-11.

12. Bensaad K, Favaro E, Lewis CA, Peck B, Lord S, Collins JM, et al. Fatty acid uptake and lipid storage induced by HIF-1a contribute to cell growth and survival after hypoxia-Reoxygenation. Cell Rep. 2014;9:349-65.

13. Hoang-Minh LB, Siebzehnrubl FA, Yang C, Suzuki-Hatano S, Dajac K, Loche T, et al. Infiltrative and drug-resistant slow-cycling cells support metabolic heterogeneity in glioblastoma. EMBO J. 2018;37:e98772.

14. Negendank WG, Sauter R, Brown TR, Evelhoch JL, Falini A, Gotsis ED, et al. Proton magnetic resonance spectroscopy in patients with glial tumors: a multicenter study. J Neurosurg. 1996;177:449-58.

15. Yue S, Li J, Lee S-Y, Lee HJ, Shao T, Song B, et al. Cholesteryl Ester accumulation induced by PTEN loss and PI3KNAKT activation underlies human prostate Cancer aggressiveness. Cell Metab. 2014;19:393-406.

16. Indira Chandran V, Welinder C, Månsson A-S, Offer S, Freyhult E, Pernemalm $M$, et al. Ultrasensitive immunoprofiling of plasma extracellular vesicles identifies syndecan-1 as a potential tool for minimally invasive diagnosis of glioma. Clinical Cancer Res. Jan 24. doi: https://doi.org/10.1158/1078-0432. CCR-18-2946.

17. Enroth S, Johansson A, Enroth SB, Gyllensten U. Strong effects of genetic and lifestyle factors on biomarker variation and use of personalized cutoffs. Nat Commun. 2014;5:127rv3.

18. Larssen P, Wik L, Czarnewski P, Eldh M, Löf L, Ronquist KG, et al. Tracing cellular origin of human exosomes using multiplex proximity extension assays. Mol Cell Proteomics. 2017;16:502-11.

19. Clark MJ, Homer N, O'Connor BD, Chen Z, Eskin A, Lee H, et al. U87MG decoded: the genomic sequence of a cytogenetically aberrant human Cancer cell line. PLoS Genet. 2010;6:e1000832.

20. Michiels C, Tellier C, Feron O. Cycling hypoxia: a key feature of the tumor microenvironment. Biochim Biophys Acta. 2016;1866:76-86.

21. Londos C, Brasaemle DL, Schultz CJ, Segrest JP, Kimmel AR. Perilipins, ADRP, and other proteins that associate with intracellular neutral lipid droplets in animal cells. Semin Cell Dev Biol. 1999;10:51-8.

22. Kaelin WG Jr. The von Hippel-Lindau tumour suppressor protein: $\mathrm{O} 2$ sensing and cancer. Nat Rev Cancer. 2008:8:865-73.

23. Semenza GL. Regulation of cancer cell metabolism by hypoxia-inducible factor 1. Semin Cancer Biol. 2009;19:12-6.

24. Mayr B, Montminy M. Transcriptional regulation by the phosphorylationdependent factor creb. Nat Rev Mol Cell Biol. 2001;2:599-609.

25. Barresi V, Mondello S, Branca G, Rajan TS, Vitarelli E, Tuccari G. p-CREB expression in human gliomas: potential use in the differential diagnosis between astrocytoma and oligodendroglioma. Hum Pathol. 2015:46:231-8.

26. Chhipa RR, Fan Q, Anderson J, Muraleedharan R, Huang Y, Ciraolo G, et al. AMP kinase promotes glioblastoma bioenergetics and tumour growth. Nat Cell Biol. 2018;20:823-35.

27. Wu D, Zhau HE, Huang WC, Iqbal S, Habib FK, Sartor O, et al. cAMPresponsive element-binding protein regulates vascular endothelial growth factor expression: implication in human prostate cancer bone metastasis. Oncogene. 2007;26:5070-7

28. Ausman II, Shapiro WR, Rall DP. Studies on the chemotherapy of experimental brain tumors: development of an experimental model. Cancer Res. 1970;30:2394-400.
29. Chen Z, Feng X, Herting CJ, Garcia VA, Nie K, Pong WW, et al. Cellular and molecular identity of tumor-associated macrophages in glioblastoma. Cancer Res. 2017;77:2266-78.

30. Véniant MM, Withycombe S, Young SG. Lipoprotein size and atherosclerosis susceptibility in Apoe(-/-) and Ldlr(-/-) mice. Arterioscler Thromb Vasc Biol. 2001;21:1567-70.

31. Piedrahita JA, Zhang SH, Hagaman JR, Oliver PM, Maeda N. Generation of mice carrying a mutant apolipoprotein $\mathrm{E}$ gene inactivated by gene targeting in embryonic stem cells. Proc Natl Acad Sci U S A. 1992;89:4471-5.

32. Quail DF, Joyce JA. The microenvironmental landscape of brain tumors. Cancer Cell. 2017;31:326-41.

33. Gabrusiewicz K, Rodriguez B, Wei J, Hashimoto Y, Healy LM, Maiti SN, et al. Glioblastoma-infiltrated innate immune cells resemble M0 macrophage phenotype. JCI Insight. 2016;1:1-32.

34. Hambardzumyan D, Gutmann DH, Kettenmann H. The role of microglia and macrophages in glioma maintenance and progression. Nat Neurosci. 2016;19:20-7.

35. Broekman ML, Maas SLN, Abels ER, Mempel TR, Krichevsky AM, Breakefield XO. Multidimensional communication in the microenvirons of glioblastoma. Nat Rev Neurol. 2018;14:482-95.

36. Müller A, Brandenburg S, Turkowski K, Müller S, Vajkoczy P. Resident microglia, and not peripheral macrophages, are the main source of brain tumor mononuclear cells. Int J Cancer. 2015:137:278-88.

37. Pyonteck SM, Akkari L, Schuhmacher AJ, Bowman RL, Sevenich L, Quail DF, et al. CSF-1R inhibition alters macrophage polarization and blocks glioma progression. Nat Med. 2013;19:1264-72.

38. Mantovani A, Marchesi F, Malesci A, Laghi L, Allavena P. Tumourassociated macrophages as treatment targets in oncology. Nat Rev Clin Oncol. 2017;14:399-416.

39. Psychogios N, Hau DD, Peng J, Guo AC, Mandal R, Bouatra S, et al. The human serum metabolome. PLoS One. 2011;6:e16957.

40. Von Eckardstein A, Rohrer L. Transendothelial lipoprotein transport and regulation of endothelial permeability and integrity by lipoproteins. Curr Opin Lipidol. 2009;20:197-205.

41. Tabas I, García-Cardeña G, Owens GK. Recent insights into the cellular biology of atherosclerosis. J Cell Biol. 2015;209:13-22.

42. Lauby-Secretan B, Scoccianti C, Loomis D, Grosse Y, Bianchini F, Straif K. Body fatness and Cancer - viewpoint of the IARC working group. N Engl J Med. 2016:375:794-8.

43. Niedermaier T, Behrens G, Schmid D, Schlecht I, Fischer B, Leitzmann MF. Body mass index, physical activity, and risk of adult meningioma and glioma. Neurology. 2015;85:1342-50.

44. Zhang D, Chen J, Wang J, Gong S, Jin H, Sheng P, et al. Body mass index and risk of brain tumors: a systematic review and dose-response metaanalysis. Eur J Clin Nutr. 2016;70:757-65.

45. Benson VS, Pirie K, Green J, Casabonne D, Beral V. Lifestyle factors and primary glioma and meningioma tumours in the million women study cohort. Br J Cancer. 2008;99:185-90.

46. Moore SC, Rajaraman P, Dubrow R, Darefsky AS, Koebnick C, Hollenbeck A, et al. Height, body mass index, and physical activity in relation to glioma risk. Cancer Res. 2009:69:8349-55.

Ready to submit your research? Choose BMC and benefit from

- fast, convenient online submission

- thorough peer review by experienced researchers in your field

- rapid publication on acceptance

- support for research data, including large and complex data types

- gold Open Access which fosters wider collaboration and increased citations

- maximum visibility for your research: over $100 \mathrm{M}$ website views per year

At $\mathrm{BMC}$, research is always in progress.

Learn more biomedcentral.com/submissions 